4 norden 



\section{Unified Reporting to the Nordic Product Registers}

Per Henrik Johansen, COWI AS

TemaNord 2009:538 


\section{Unified Reporting to the Nordic Product Registers}

TemaNord 2009:538

(C) Nordic Council of Ministers, Copenhagen 2009

ISBN 978-92-893-1874-7

Print: Kailow Express ApS

Printed on environmentally friendly paper

This publication can be ordered on www.norden.org/order. Other Nordic publications are available at www.norden.org/publications

Printed in Denmark

Nordic Council of Ministers

Store Strandstræde 18

DK-1255 Copenhagen K

Phone (+45) 33960200

Fax (+45) 33960202

www.norden.org

\section{Nordic Council}

Store Strandstræde 18

DK-1255 Copenhagen K

Phone (+45) 33960400

Fax (+45) 33111870

\section{Nordic co-operation}

Nordic cooperation is one of the world's most extensive forms of regional collaboration, involving Denmark, Finland, Iceland, Norway, Sweden, and three autonomous areas: the Faroe Islands, Greenland, and Åland.

Nordic cooperation has firm traditions in politics, the economy, and culture. It plays an important rol in European and international collaboration, and aims at creating a strong Nordic community in a strong Europe.

Nordic cooperation seeks to safeguard Nordic and regional interests and principles in the global community. Common Nordic values help the region solidify its position as one of the world's most innovative and competitive. 


\section{Content}

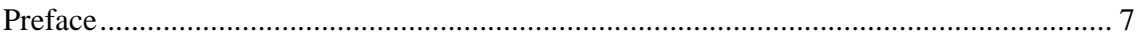

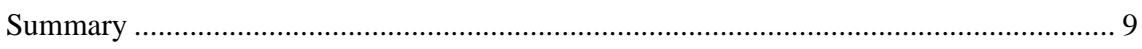

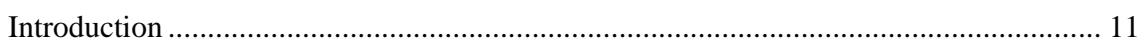

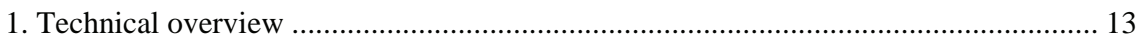

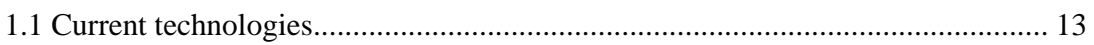

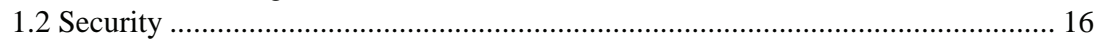

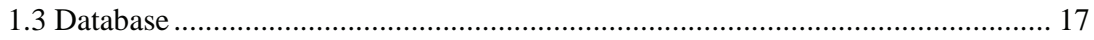

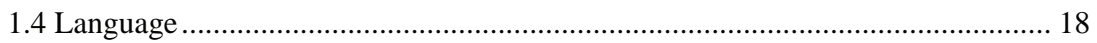

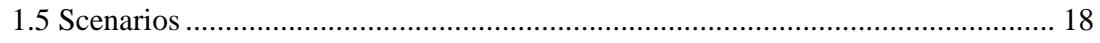

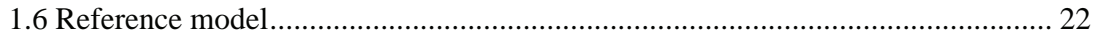

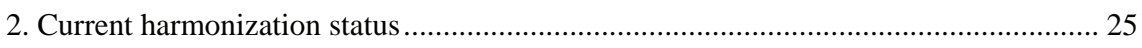

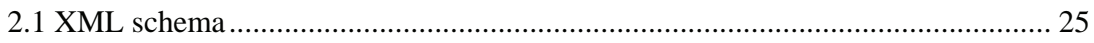

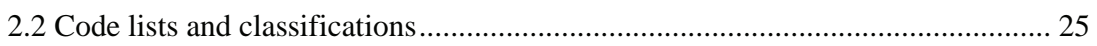

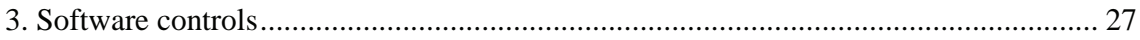

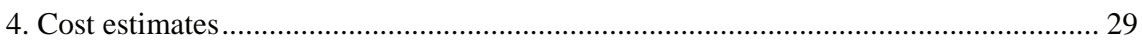

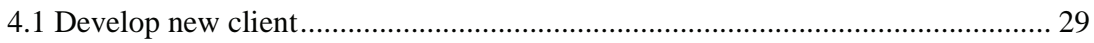

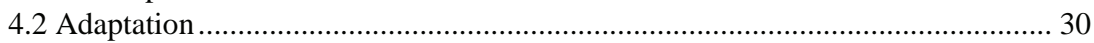

4.3 Conclusion - adaptation vs. new development................................................... 32

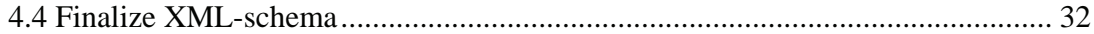

4.5 Development costs for the Product Registers ...................................................... 33

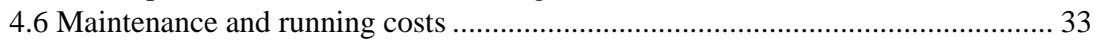

4.7 Project management and administration............................................................. 33

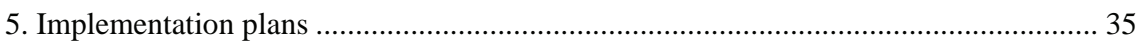

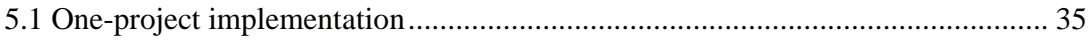

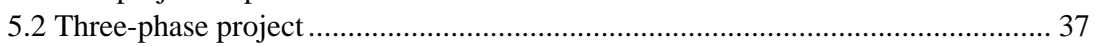

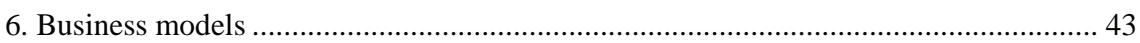

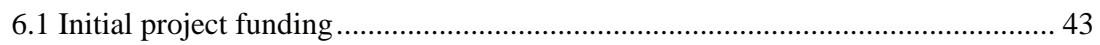

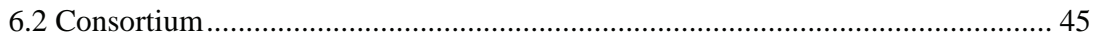

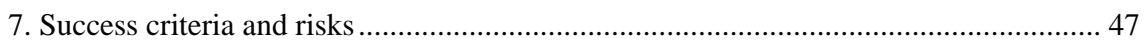

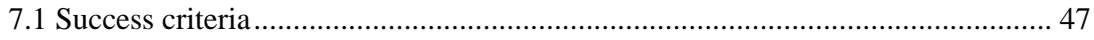

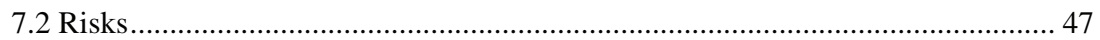

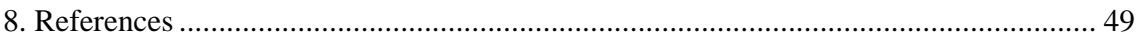

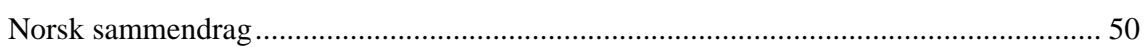





\section{Preface}

The Nordic Product Registers has since 2003 been working on harmonizing the reporting process for companies in the Nordic countries. A questionnaire was sent to a selection of companies (The Nordic Product Registers, 2004) concludes that this is welcomed by the companies and it will reduce their workload.

The objective of this report is to clarify the technical solution needed to accommodate the harmonization and to map the current status of the process.

The project was funded by the Nordic Council of Ministries through the Nordic Chemicals Gruop. The conclusions presented in this report are expressions of the author's opinions and do not necessarily reflect the views of the Nordic Council of Ministers.

Project group:

Sven Nielsen (Denmark), Einar Hovde (Norway), Eva Ljung (Sweden) 



\section{Summary}

This report describes a software model for implementing a joint reporting tool for the Nordic Product Registers. The tool will be used by the chemical industries in the Nordic Countries to report chemical products to the Product Registers.

There exist various methods for implementing a solution to afford this, but the conclusion in this report is that a new client based on the fatclient paradigm should be developed.

The report also contains cost estimates for the development and proposes two development plans for implementation. 



\section{Introduction}

The chemical industry in the Nordic countries has for years expressed wishes for a simpler method for reporting chemical products to the Nordic Product Registers. This new solution should offer joint reporting to the Product Registers and the reporting should be done electronically.

The Nordic Product Registers are collaborating with harmonizing the reporting process. They have been granted money to investigate a software-model for this solution from the Nordic Council of Ministers. This work is led by the Harmonization Group.

This report contains the discussion, conclusions and description of the proposed reference software model. This model will be used for implementing the harmonized reporting from the chemical industries in the Nordic countries.

The organisation of the report is as follows:

- Chapter 1 (Technical overview) looks at various technical possibilities and constraints for implementing the reporting tool. It concludes with a reference implementation model.

- Chapter 2 (Current harmonization status) describes the progress made with the harmonization and estimates the resources needed to complete this activity.

- Chapter 3 (Software controls) gives a rough overview of the software controls that needs to be implemented in the reporting tool.

- Chapter 4 (Cost estimates) breaks the implementation down in estimates the resources needed to develop the reporting tool. Also, a conclusion is made whether the path of adapting already existing software components versus develop a new tool is discussed and concluded.

- Chapter 5 (Implementation plan) presents two plans for development of the reporting tool.

- Chapter 6 (Business models) looks at how to fund the development of the reporting tool.

- Chapter 7 (Success criteria and risks) presents some overall point on how to measure the success of the project and some pitfalls to avoid. 



\section{Technical overview}

This chapter gives an overview of the different technical solutions used today by the Nordic Product Registers. First a summarized overview of each country's implementation is given, followed by a summary of security and language issues.

Also a general approach to the reporting task is given; we present two different scenarios as examples on how the harmonization of technical platforms can be solved. The scenarios use the fat and thin client architectures.

Based on the current technology and the discussion of scenarios, one preferred and suggested solution is given. This will be the technical reference platform which the rest of the report will take into account; all cost estimates, implementation schedules, etc, will be based on implementing the reference platform.

\subsection{Current technologies}

In order to give an understanding of the reporting process and technologies, a description of the current solutions in the countries is given. We will give an overview of the whole process, both reporting and dissemination processes are covered, but with emphasis on the former.

\subsubsection{Denmark}

The description of the Danish solution is based on technical system descriptions supplied by the Danish Product register (Danish Product Register, 2008), and information supplied in meetings in the steering group.

Denmark has implemented a solution where the companies fill out information to be submitted locally on their own computer, with their own data registration tools - domain systems. The data from the domain systems are processed with a local application, which adds administrative data such as contact information, attachments etc. The end-result from this process is a set of XML files which is formatting according to XML schemas provided by the Danish Product register. These schemas are based on the harmonization effort from the Harmonization Group.

Before the data is sent from the company to the Product Register, another application, the ProbasFrontend, validates, encrypt, and signs the data. The ProbasFrontend also submits/sends the data over http/https to the Product Register. 
The figure below shows a summary of the process and the components involved.

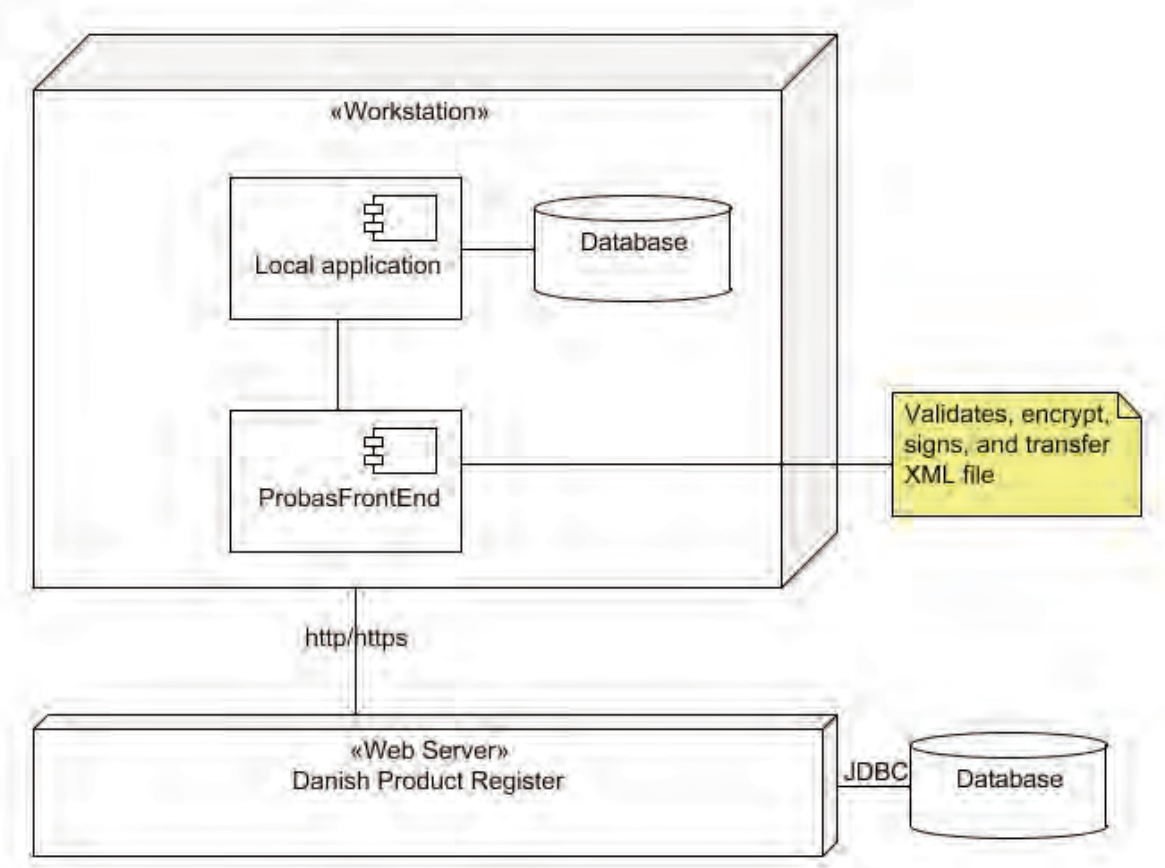

Maintenance and distribution of the reporting solution is done by the Danish Product Register. Changes in the XML schemas are distributed to the companies from the Product Register website.

The reporting companies are also entitled to receive data from the Danish Product Register. The principle is that a company can only view their own data, and only data which they have sent to the Product Register. This means that data revised by the Product Register can not be disseminated back to the company.

\subsubsection{Norway}

The description of the Norwegian solution is based on conversations in the steering group and on a demonstration given in the premises of the Norwegian Product Register in February 2008.

Norway has developed a client specifically to fill in and send data from companies to the Norwegian Product Register. The basis of this application is a locally installed Microsoft Access database. This database is used to both store data entered by the companies, and to store classifications used by the application.

On top of the database, the application has a rich GUI (Graphical User Interface) which controls the workflow and performs data validation. The user interacts with this application just like any other windows-based system. The controls are handled during registration so feedback is given instantly. All data is saved back to the local database, so that companies 
can keep a history of their product, and access previous recorded data for later reporting.

Data is sent encrypted and digitally signed to the Norwegian Product Register as an XML file. The schema of this file is loosely based on the work from the Harmonization Group.

When the Norwegian needs to disseminate new code list, classifications, etc to the companies, they do this by sending an updated version of the Access database. No previously reported data is included.

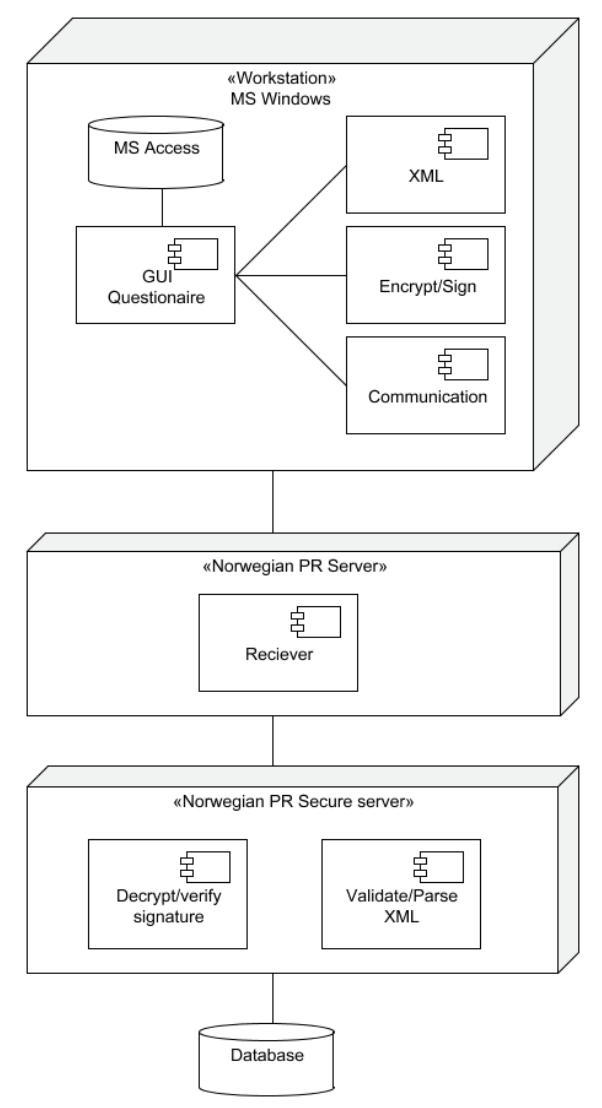

\subsubsection{Sweden}

Sweden has quite a different approach than the two other Product Registers. They have implemented a web-based system where the companies identify themselves with an electronic id.

The system has web-forms to register new products and information regarding these products. In addition the users can upload CSV - files which contain product data. These CSV files can easily be produced by Microsoft Excel or by export from in-house systems at the companies. 


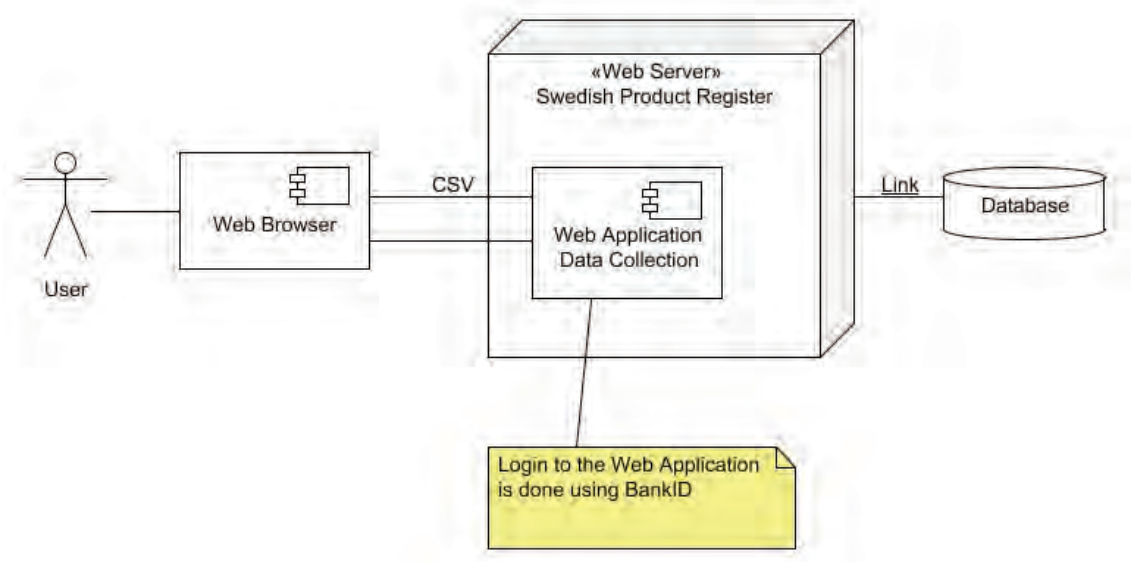

Since the Swedish system is web-based, all data is stored centrally at the Swedish Product Register. This has the advantage that the Product Register has access to the total of reported information online at all times, and the Product Register can perform controls and validation on them and give feedback to the reporting companies through the web interface.

With a centralized solution, update of metadata (code lists, classifications, controls, etc) is easy to maintain, since all updates are done at one central point and one update may affect all companies at the same time.

\subsection{Security}

The data that is reported to the Product Registers are highly sensitive, especially to the companies that own the products. Security is therefore essential; the product registers must be trusted to keep the information safe for intruders and to authenticate the sender. The security issues can be divided into two areas: transfer and storage, where transfer is the electronic sending of product data to the Product Registers, while storage is how the Product Registers receive and store the data.

\subsubsection{Digital signatures and encryption}

Today all three Product Registers use the same methods to handle security for data transfer: encryption and digital signing. However, they all use different technical implementations and providers. Regarding encryption, the different platforms are expected to be interoperable. Digital signatures, on the other hand, could cause some problems, especially since this involves trusting and issuing certificates that is expected to work on an international arena.

In the current reporting frameworks, all three Product Registers use different security solutions and certificates. Both the Danish and Swedish Product Registers use nationally approved solutions, while Norway issues their own certificates, since Norway does not have a national solution specified yet. 


\begin{tabular}{ll}
\hline $\begin{array}{l}\text { Product } \\
\text { Register }\end{array}$ & Certificate solution \\
\hline Denmark & $\begin{array}{l}\text { National standard for digital signatures (http://www.digitalsignatur.dk/). Certificates are } \\
\text { handled by TDC. Denmark also accepts GlobalSign for international users. }\end{array}$ \\
Norway $^{1}$ & $\begin{array}{l}\text { The Norwegian Product Register issues their own certificates, since Norway do not yet } \\
\text { have their own standard. However, the Norwegian banks has started distribution of } \\
\text { their own certificates; BankID (http://www.bankid.no/) }\end{array}$ \\
Sweden & $\begin{array}{l}\text { National standard for digital signatures (http://www.notisum.se/rnp/SLS/LAG/ } \\
\text { 20000832.HTM). Certificates are supplied by BankID and Telia. } \\
\text { Also see http://www.e-legitimation.se }\end{array}$ \\
\hline
\end{tabular}

A report made by the Norwegian government (NOU 2001:10, chapter 10.1) raises the following issues concerning digital signatures and interoperability:

- One should be able to handle certificates from an arbitrary issuer in a meaningful way (validate signature, access the contents of the certificate, etc).

- One should be able to have certain knowledge about the issuer's public key used to sign the certificate.

- Work with different security products from different suppliers/vendors.

- One must decide the trust-level of a given certificate to tell if it can be used for the intended purpose.

\subsubsection{Storage}

Typically, data is at least stored twice in the current solution. Once when the questionnaire is filled in, so that the user may retrieve it at a later point, copy the data to a new questionnaire, etc. The second storage is when the data is retrieved by the product register. The latter storage is governed by national restrictions and regulations.

The important fact is that a product register can not store data reported to another nation. For example, Sweden may not, under any circumstance, have data which belongs to the Norwegian or Danish Product Register. This will have impact on the final solution, since all data must be kept only by the receiving register.

\subsection{Database}

Since the product registers already have started the harmonization process, it is reasonable to assume that they will have the same complexity in their databases. Of course there will be deviations between the countries, but in general they will follow the same suite. Therefore, in order to say

\footnotetext{
${ }^{1}$ The Norwegian Product Register follows strict guidelines and rules from the Norwegian National Security Authority for storage and treatment of the reported data.
} 
something about the database complexity, we have looked at the KEOPS database from Sweden (Kemikalieinspektionen, 2008).

The database consists of 32 tables with 37 relations. A total of 131 fields are used in the tables.

\subsection{Language}

Each of the involved Product Registers, Denmark, Norway and Sweden, has their own national language, and this also applies to companies reporting to the different Product Registers. This means that each of these languages must be supported by the reporting tool(s), thus all text in the application (labels, help, etc) must be represented in three different languages.

Despite the language issues, the harmonized solution will use English as its main language. The only exception to this could be that some code lists or/and classifications may include national texts.

\subsection{Scenarios}

This chapter looks at different approaches on how to design a joint harmonized reporting tool for the Product Registers.

One important point to outline before the scenarios are discussed is the fact that the in-house handling of the data will remain unchanged. That is, each of the Product Registers will receive and handle the encrypted and digitally signed XML file - there will be no shared delivery point for the data. Thus, the scope of the scenarios will cover the interaction and process from the side of the reporting party until it is received by a Product Register.

The Danish and Swedish Product Registers also disseminate product data back to the reporting companies. This process is not covered in the scenarios.

The common elements and process steps in the scenarios might be summarized as follows:

- The party fills inn an advanced questionnaire with the data requested by the Product Registers. Depending on which national Product Register that is the receiver, the data will have a light difference.

- The data is validated (software controls)

- If the data is consistent with the validation rules, it is sent to the receiving Product Register in an XML format. This format follows the same schema regardless of which Product Register is the receiver (harmonized format). The data is of course encrypted and signed before sent to the Product Register. 
- The Product Register receives the data, check signatures, decrypts, and validates the data. If this process succeeds, the data is picked up by internal processes at the Product Register.

The figure below illustrates this process.

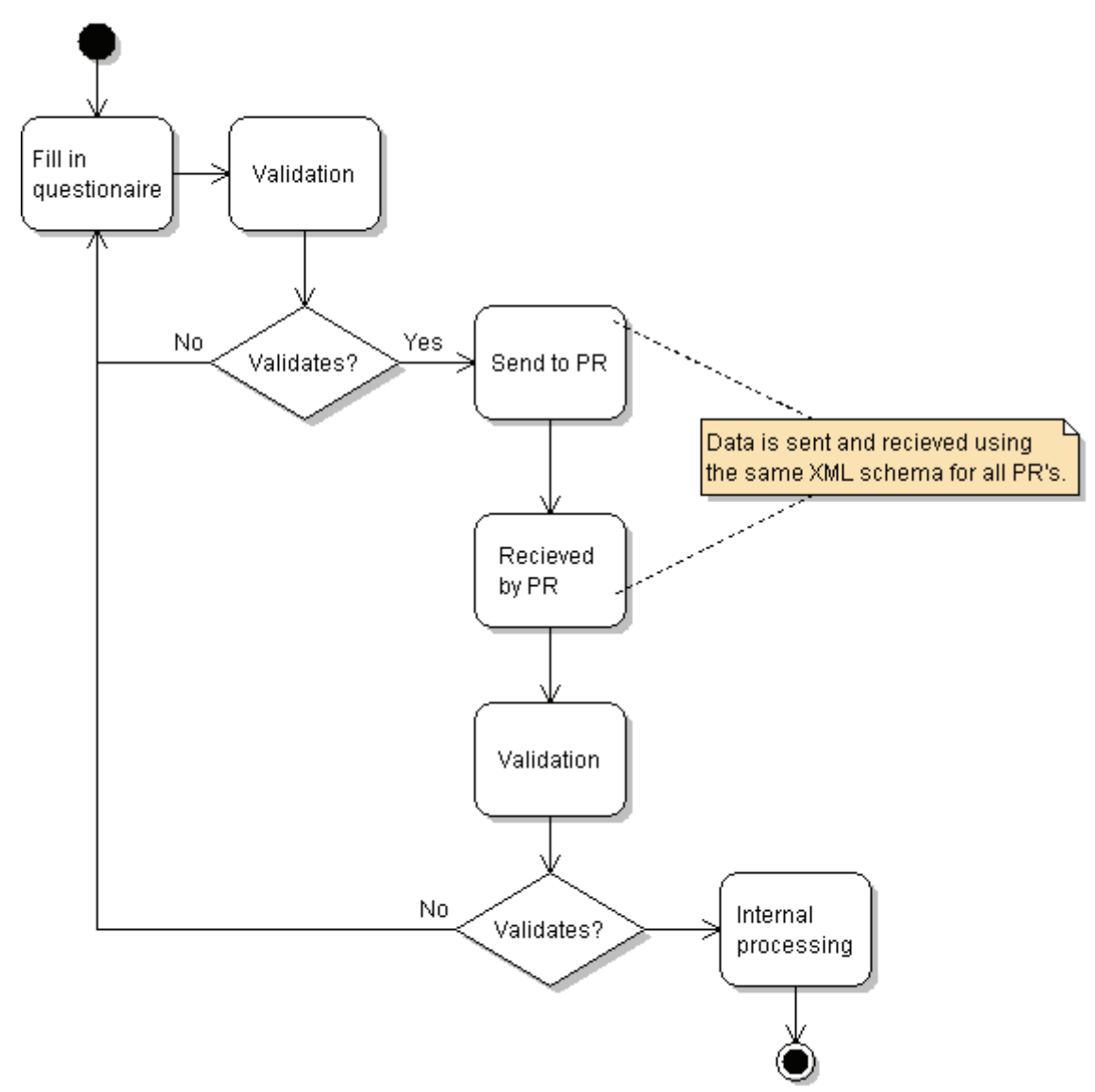

The following logical software modules can be identified from the above process:

- Data collection.

Data might exist in several sources at the reporter: local databases, spreadsheets, on paper, etc. This module will collect the data needed to report to the Product Registers.

- Validation.

This module will validate the data according to rules specified by the Product Registers.

- Transformation.

The data is transformed into a common XML format. The Product Registers will specify this format. 
- Security.

The XML-file is encrypted and signed.

- Communication.

Sends the data to the Product Registers.

In addition to collecting data, the Product Registers needs to update the reporting software with new code lists and classification. Also new validation rules needs to be distributed to the application; this might include upgrade/installation of software components, depending on the client implementation.

\subsubsection{Fat clients}

This scenario will look at applications known as fat clients - applications where the logic and functionality is provided independent of the server. Typically a fat client is installed and runs within the desktop environment on the user's computer and keeps a connection to the server to transfer data only. Both Denmark and Norway has implemented this type of architecture.

The general advantages of a fat-client-architecture are:

- Simpler server implementations and server requirements.

Since most of the logic and processing resides in the client, the server performance does not have to be so high.

- Work offline.

Since the client does not need to be connected to the server at all times and all functionality, such as user interaction and data processing, is implemented in the client, the user can work offline.

- Better multimedia performance.

Since the client can make use of the full power of the client, its performance will generally be better for data processing tasks.

- More flexibility.

The client can take full advantage of the underlying hardware and operating system resources.

Implementing a reporting application for the Product registers will require that implementation of all the modules from chapter 1.4 in the client. This means that the Product Registers only need to implement the server side functionality - the entry point to which the data is sent. This functionality should already exist at each Product Register and could be reused with minor changes, like implement handling of the new XML format. 


\subsubsection{Thin clients}

A thin client - in the software domain - usually describes an application where most of the logic and computer processing is done on the server side of the application. The client resides at the user's computer and only handles basic operations. It is usually hosted in another program/virtual machine. Typically in modern thin clients, the application runs in a webbrowser, where the user interface and interaction is implemented in HTML $^{2} /$ Javascript and all data is passed to and from the server ${ }^{3}$. The server side hosts all the business logic and acts like a data store. The Swedish Product Register implements this architecture.

The advantages of using a thin-client-architecture are:

- Lower costs.

Since all administration is done on the server side it is easier to administer.

- Security. Since no data is kept on the client side, it is easier to protect and secure.

- Maintenance

All changes done to the software, and hardware, on the server side will also affect every client that uses it, so updating, security fixes, etc is easier to administer.

- Availability.

Since the application runs in a web-browser (or other virtual software), it can be accessed in principle from everywhere without the need to install additional software on the user's computer.

\subsubsection{Architecture constraints and scenario conclusion}

As pointed out in 1.2.2, due to security constraints, for example in Norway, it will be impossible to store Norwegian product information in a database residing at the Swedish product register. This means that each Product Register must have their data collection server. This also means that the thin client option as described in 1.5.2 not will be an option, since this scenario is based on the fact that data from different countries will be stored on the same server. Thus, the most viable scenario will be based on the fat client approach.

\footnotetext{
${ }^{2}$ Hypertext Markup Language

${ }^{3}$ Other thin client solutions also exists, like accessing a remote computer through "terminal programs”, for example CITRIX and VNC, etc. These solutions are not covered in this report.
} 


\subsection{Reference model}

As stated in 1.5.3, the reference platform will build upon fat-client architecture. It is made up by the following logical modules:

- GUI

This is the main part of the client. All user interaction, data registration, automatic controls (through form-fill-in) if handled by this module. It will with all probability be broken into further submodules/ components during system design.

- XML

This module handles XML generation and validation

- Security Encryption and signing will be the responsibility of this module.

- Communication

Data transfer to the National Product Registers will be sent over http/https. This module will also handle all updates from the NPR's; software updates, code list, etc.

Regarding security (bullet point 3) the obvious question arise; is it feasible to implement a common security solution that the individual Product Registers will be able to handle? One solution would be to make all reporting companies to buy certificates from the same provider, like GlobalSign or VeriSign. That way the product registers will be able to make use of the same elements in the certificates and use the same methods to verify them. Also, the same software components can be shared.

It is expected, however, that a common EU certificate is expected to be developed in the future. 


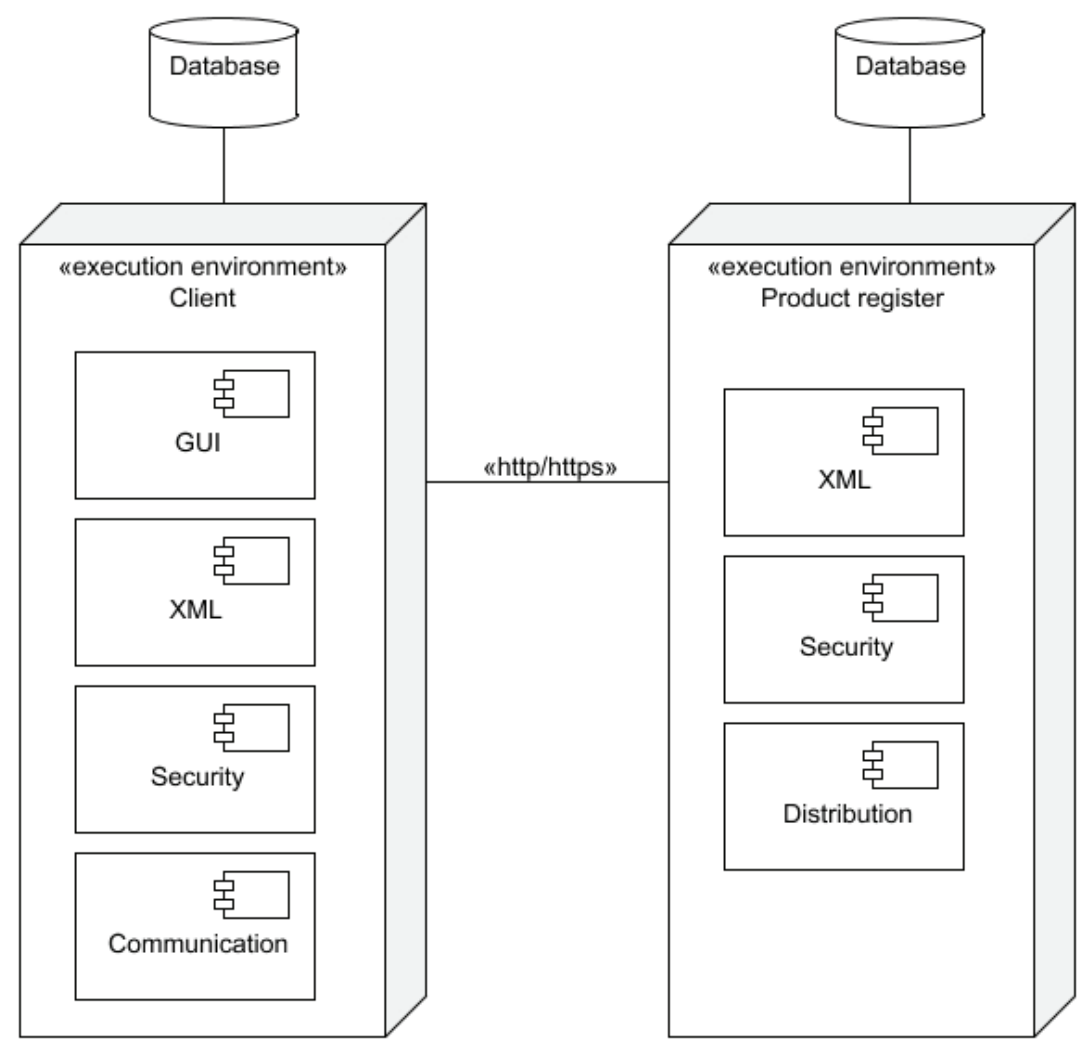

The National Product Registers will also have modules corresponding to the client, but it will be the responsibility of each National Product Register to implement this according to the agreed upon interfaces. These will be designed in the final specification of the project. 



\section{Current harmonization status}

This chapter tries to give an overview and estimate on the current status of the harmonization process, mainly this consists of the definition of the XML schema, which will be used as a common document format.

We will also look at the most common code lists and classifications and state where there are differences and which ones that is the same in all countries.

\subsection{XML schema}

Extensive work to implement a harmonized XML schema has been underway for some years, and has already come a long way. A document specifying the elements to be included has been written (The Nordic Product Registers, 2006) and a survey of which data the Product Registers receives has been carried out (The Nordic Product Registers, 2007). Also, both the Danish and the Norwegian Product Registers use a variant of the XML schema at present date.

The work is believed to be almost final. The data coverage is almost complete, but needs to be validated and quality assured. Since XML schemas which is similar to the harmonized schema is in use, the basis of the schema is already made.

It is roughly estimated that 30 working days is needed to complete the above process and define an XML schema to be used in the final reporting solution. This includes the work needed to complete the overview of which data element to include in the schema, not just complete the schema definition. The estimate includes resources from all three Product Registers.

\subsection{Code lists and classifications}

The harmonization of classifications and code list is complete. That is, all classifications and code lists that are in use are based on international standards. Some of these standards, for instance NACE codes, contain methods/definition to use national extensions. The Nordic Product Registers, to some extent, use these options.

In addition, pure national code lists are in use. An example of this is postal codes.

Since a harmonized solution will not change the use of classifications and code lists, the main task will be to get an overview of which are used 
and how they are used. The list of code lists and classifications in use today is quite limited (see chapter 3) and to make a complete listing of them, and their usage, should be quite trivial. 


\section{Software controls}

A major part in the existing reporting frameworks is controls. These controls check the data for inconsistencies and validate their formats.

Software controls is handled both on the client and on the server side. The latter may contain more controls than the former, for instance controls against previous reported data might be done to uncover inconsistence in the data. Thus the server side may have a more rigid and numerous validations.

Based on the latest description of the XML-schema (The Nordic Product Registers, 2006) it is estimated that 172 controls exists. These controls are mainly controls validating single fields, i.e. length of text fields, date formats, number formats, etc. There also exists a few modulus controls. These controls will be invoked both by the client during the actual fill-in of the data in the GUI and as part of validation of the XML data.

In addition to these controls, the client must check the data against code lists and classifications. It is recommended that this is done during form fill-in. These classifications and lists will not be $100 \%$ harmonized, some will even be disjoint between the countries, so the client must be able to use a different code list depending on who the recipient is, for example postal codes.

The most important code lists and classifications at the time of writing are:

- Postal codes and postal places

- NACE

- Customs clearance number

- UCN

- CAS 



\section{Cost estimates}

In order to give an overview of the total cost of the project, we look at both the development of a new client and the adaptation of the existing clients. The first will have one cost estimate while the latter will include one estimate per country. The country specific estimates only include work on their respective clients, not adaptations needed to be made to the Product Registers in-house systems. Note that these are rough estimates only, but should give an overview and indication of the total workload for the different solutions.

There are also costs by implementing the solutions, whether it is a new client or adaptation to existing clients, for the Product Registers. These costs are estimated in chapter 4.5.

All estimates are done in man hours.

\subsection{Develop new client}

The following criteria have been taken into account in the estimate:

- The client will have a database consisting of $30-40$ tables.

- The client will have $30-40$ forms with various degree of form logic.

- Integration with new security solution.

- Communication with the product registers.

- Update function - new version of software and new versions of code lists. 
The cost will then be as follows:

\begin{tabular}{lr}
\hline Task & Man hours \\
\hline Development & 1400 \\
GUI & 264 \\
Logical functions (security, communication) & 368 \\
Database design & 160 \\
Database layer & 440 \\
Other (XML implementation) & 48 \\
Misc. & 828 \\
Testing & 280 \\
Documentation & 182 \\
Technical documentation & 84 \\
Training & 49 \\
Risk overhead, development & 140 \\
Installation & 56 \\
Acceptance test & 37 \\
Project management, risk overhead & 735 \\
Project management (15\%) & 334 \\
Quality Assurance (3\%) & 67 \\
Risk (15\%) & 334 \\
Total & 2963 \\
\hline
\end{tabular}

\subsection{Adaptation}

The cost to adapt the existing solutions to a new framework will be individual to each country. This is due to the fact that each of the solutions technically differs from each other. Thus one cost estimate is presented for each Product Register. These estimates are however uncertain, since the implementation details of the solutions have not been studied - the estimates are therefore based solely on guesses according to oral and written descriptions of the system.

The most common and obvious adaptations that need to be done include:

- GUI changes - new data needs to be registered. This includes country specific information. Logic and registration fields must be added.

- Local data store - since new data will be reported, the local data store must be able to retrieve and keep this additional information.

- Communication - the client will have to send its data to two more receivers.

- Code lists - each country will have their own code list in addition to the harmonized ones.

- XML-Schema - the reporting format will be harmonized and changes must be made in the client.

- Security - new certificates will be used and possibly also a new security model.

Each product register will have to run an own project which supervises and specifies the adaptations. 


\subsubsection{Denmark}

The Danish solution is already implemented using the fat client scenario. This means that most of the functionality is already in place.

Denmark uses a variation of the XML-schema, and we expect only minor changes to adapt to the harmonized schema.

Code lists and changes to the XML schema is already disseminated to the client from the central server of the Danish product register. Only minor changes to this solution are expected in a new client, but have to consider that two more sources will be added.

\begin{tabular}{lr}
\hline Task & Man hours \\
\hline Development & $\mathbf{2 5 0}$ \\
GUI & 28 \\
Logical functions (security, communication) & 144 \\
Database design & 10 \\
Database layer & 28 \\
Other (XML implementation) & 40 \\
Misc. & $\mathbf{1 4 6}$ \\
Testing & 50 \\
Documentation & 32 \\
Technical documentation & 15 \\
Training & 8 \\
Risk overhead, development & 25 \\
Installation & 10 \\
Acceptance test & 6 \\
Project management, risk overhead & $\mathbf{1 3 0}$ \\
Project management (15\%) & 59 \\
Quality Assurance (3\%) & 12 \\
Risk (15\%) & 59 \\
Total & $\mathbf{5 2 6}$ \\
\hline
\end{tabular}

\subsubsection{Norway}

The Norwegian client is implemented as a fat client. It already uses XML to report data, but which schema that is in use is uncertain.

When updating code list etc, Norway distributes a new database to the companies. This means that a new distribution scheme has to be implemented in order to get updates from the other product registers. 


\begin{tabular}{lr}
\hline Task & Man hours \\
\hline Development & 329 \\
GUI & 28 \\
Logical functions (security, communication) & 216 \\
Database design & 12 \\
Database layer & 33 \\
Other (XML implementation) & 40 \\
Misc. & 190 \\
Testing & 65 \\
Documentation & 42 \\
Technical documentation & 19 \\
Training & 11 \\
Risk overhead, development & 32 \\
Installation & 13 \\
Acceptance test & 8 \\
Project management, risk overhead & 172 \\
Project management (15\%) & 78 \\
Quality Assurance (3\%) & 16 \\
Risk (15\%) & 78 \\
Total & 691 \\
\hline
\end{tabular}

\subsubsection{Sweden}

The Swedish Product Register, since the existing solution is based on thin client architecture (web-based), will have the most dramatic adaptation process. In practice, and for estimation purpose, the adaptation will consist of developing a new client, much like in 4.1. The cost will therefore be close to the estimate given in 4.1.

\subsection{Conclusion - adaptation vs. new development}

The uncertainties of adapting the existing clients in the respective countries are quite high. Also, Sweden most probably must develop a new solution due to security restrictions as outlined in 1.2.2, thus the total cost of adaptation will be greater than to develop a new client. Therefore, it is recommended to develop a new common client for joint reporting for the three product registers, as estimated in 4.1. This will keep developing costs under control and it is easier to set an end date for the project.

\subsection{Finalize XML-schema}

Much work has already been put into making a common XML-schema. Denmark already has a good solution and is the Product Register that has made most progress in this regard. Thus, the Danish solution is the natural starting point for estimating the completion of the harmonized schema.

Based on the current status given in chapter 2, the estimated time for completion is roughly 30 working days. 


\subsection{Development costs for the Product Registers}

All of the Product Registers need to make changes to the already existing in-house solutions on the receiving servers. These costs are difficult to estimate without a thorough investigation of them. This task is out of scope for this report. However, after discussions in the project group, we would like to present the following cost estimate:

\begin{tabular}{lr}
\hline Country & Man hours \\
\hline Denmark & 400 \\
Norway & 600 \\
Sweden & 800 \\
\hline
\end{tabular}

Note that these estimates can only be used as an indication on the workload and are not absolute.

\subsection{Maintenance and running costs}

Maintenance cost, as a rule of thumb, is usually set to about $10 \%$ per year of the development cost. This normally includes bug-fixing and minor enhancements to the software. There are two apparent models to finance this cost, either the product registers funds the development or the reporting companies pay for the advantage that electronic reporting gives them. Mixes of the two are of course possible - some of the cost is covered by the product registers while the companies must fund the remaining cost.

\subsection{Project management and administration}

The Product Registers also needs to manage the implementation process from their end. This will include work such as write specifications, negotiate contracts etc. It is expected that these tasks will be done by resource allocated from within the Nordic Product Registers.

\subsubsection{Specification}

From the Poduct Registers point of view, making specifications will be a major task. Both functional and technical specifications need to be made for the harmonized client. This work will involve technical and administrative personel from all three Product Registers, and will need coordination between them.

Since these specifications will use the existing solutions as basis, it is expected that most of the functionality and technical constraints are known, but needs to be formalized. It is roughly estimated that the Nordic Product Registers will use 120 man-hours for this. Since it involves a lot 
of coordination, the work is estimated to run over a period of 30 working days.

\subsubsection{Announcement}

One or more announcement will be published for the project, depending on which implementation model is used (see chapter 5). These must be prepared. It is expected that this will take about 24 hours per announcement. Since coordination between the product registers is needed, it is expected that this task will take about 10 working days.

\subsubsection{Evaluation}

Evaluation of tenders received is estimated to take about 40 hours, highly depending on the number of offers given. It is expected that this task will have a duration of 15 working days and involve resources from all three Product Registers.

\subsubsection{Negotiations}

Negotiations will include talks with potential implementers and to conclude which bidder will win the implementation process. It is estimated that it will take about 40 working hours to complete this task. It will have a duration of 10 working days.

This task is depending on how many bidders that is invited to negotiations, but it is expected that at least two will attend. 


\section{Implementation plans}

This chapter presents two implementation plans; one in which the development is done as one project, and one plan where the development is divided into three sub-projects, or phases.

The reason we have decided to present two plans is because of funding problems. The probability that the implementation of the harmonized solution can be funded as one, big project is quite small, thus the most likely scheme is to divide the project into smaller, independent projects. These will have their separate funding, but when finished will make up the complete solution.

Because of the size of the project(s), special consideration must be taken into account when advertising and awarding them. This is regulated by the European Union.

\subsection{One-project implementation}

Based on the estimates in chapter 4.1, 4.2 and 4.5, the following implementation plan has been set up. It is understood that the Harmonization Group will act as project manager for the implementation of the suggested solution.

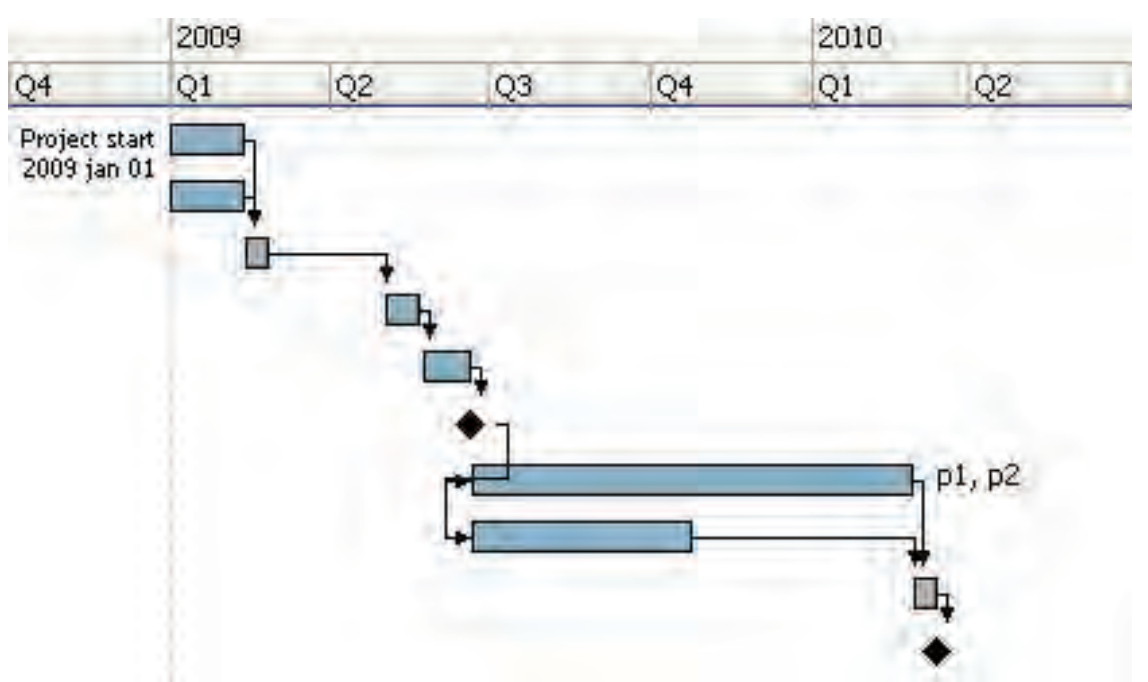

The project start is set to January 1 , 2009, as this seems the most optimistic date due to the fact that funding for the project is not in place.

The expected end is in the first quarter of 2010. 
The plan is divided into 6 tasks and 2 milestones. Some of the tasks run in parallel; task 1 and 2 (specification and harmonization), and task 5 and 6 (development). The tasks and milestones are as follows:

\section{XML schema and harmonization}

The harmonized XML schema needs to be finalized by the Nordic Product Registers. This task will be carried out in the first quarter of 2009 in parallel with task 2.

\section{Specification}

The client software and the final technical architecture need to be specified in a document. The document will describe the set of criteria, technical and others, which an implementer of the solution must conform to. This task will be carried out in the first quarter of 2009 in parallel with task 1.

\section{Announcement}

An announcement for the project has to be made. Due to the size of the contract, the announcement must be made covering all of the European Union. This task is dependent on task 1 and 2 and will be carried out in the first quarter of 2009.

\section{Evaluation}

The answers from potential implementers must be evaluated. This task depends on task 3 , and can not take place until the deadline set in the announcement is reached; therefore the earliest start is in the second quarter of 2009.

\section{Negotiations}

The Harmonization Group negotiate with one or several potentional providers. This task depends on the outcome of task 4 and will take place in the second quarter of 2009.

\section{Contract - milestone}

The first milestone is reached when a contract is made between the party who will develop the solution and the Harmonization Group. This milestone is reached in the second quarter of 2009 and depends on task 5.

7. Development-client

The development of the client software will be implemented by the contracted party according to specification (task 2). It is estimated that at least 2 resources/persons will work fulltime on the development. Estimated start is late in the second quarter of 2009, and will end in the first quarter of 2010. This task depends on task 6 . 


\section{Development - Nordic Product Registers}

The Nordic Product Register's will develop any changes needed to their architecture to meet the requirements in the specification (task 2). It is difficult to estimate how much resources each Nordic Product Register needs to use, but a rough guess is 30 days per Nordic Product Register. The Nordic Product Registers work in parallel on the development. Estimated start is late in the second quarter of 2009, and will end in the third or fourth quarter of 2009. This task depends on task 6.

\section{Roll-out-milestone}

The second milestone is reached when the solution is rolled out to the companies. It will be reached in the first quarter 2010. Following this milestone is the actual rollout to the companies. How long this will take is depended on how many and in which interval new companies arrive. Thus this is set as a milestone and end of the project period.

\subsection{Three-phase project}

In order to have an alternate implementation plan so that costs can be divided, it is suggested that the development of the solution to be split into three parts: a demonstrator, the full implementation and roll-out. Each of the parts will be executed as separate projects/phases, but they will depend on each other.

The tasks and activities listed in the three phases might be shifted. Since the reason for dividing the project is based on financial reasons, and the most costly activity is the development of the reporting client, the development activities might be moved between the phases. This way a more cost optimal split might be found. However, the phases presented in this chapter are considered to be the best route to implement the solution.

A cost estimate, based on the cost estimates in chapter 4, of each phase should be done in the specification-task before an announcement is made. This is especially so for the client-development, which is the most costly task, and which is split over all three phases. Care should be taken as to which functionality should be developed in each phase, so it will match each phase's budget. The plan presented here, suggests that most of the client functionality will be developed in phase 1 , and decline in phase 2 and 3, hence most of the client development cost is included in phase 1.

For simplicity, all phases start in Q1 for a given year; phase 1 in Q1 2009, phase 2 in Q1 2010 and phase 3 in Q1 2011. This is probably not a realistic approach since other external deadlines will exists, for example deadlines for applying for funding. It is expected that these will change. 
The duration of each phase might also vary, depending on the resources put into each task of each phase.

\subsubsection{Phase 1: Demonstrator}

The goal of this phase is to implement a demonstrator of the technical solution. A client will be developed which contains most of the user interaction and software controls. The XML schema will be finalized as part of this phase along with the data model. No security will be implemented, so the demonstrator will use dummy data only. Also, no development will be done at the receiving end at the Product Registers.

The expected start will be January 1. 2009 and the phase will end in Q4 2009.

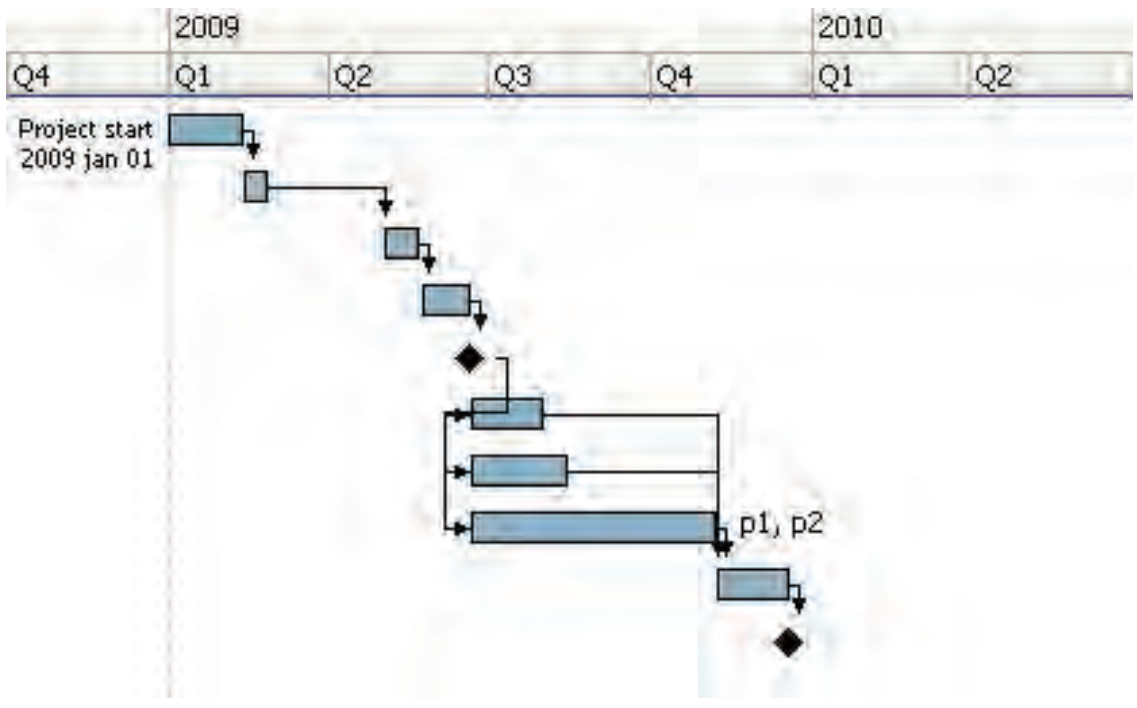

\section{Specification}

The requirements of the demonstrator need to be defined. This includes any technical and functional requirements to the solution, which includes the client and the database.

\section{Announcement}

The project will be announced in this task. It depends on task 1 .

\section{Evaluation}

The answers from potential implementers must be evaluated. This task depends on task 2.

\section{Negotiations}

The Harmonization Group negotiate with one or several potentional providers. This task depends on task 3. 


\section{Contract-milestone}

The first milestone is reached when a contract is made between the party who will develop the solution and the Harmonization Group. This milestone depends on task 4.

\section{Harmonized XML schema}

The harmonized XML schema needs to be finalized by the Nordic Product Registers. This task depends on task 5 and runs in parallel with task 7 and 8.

7. Data model

The data model must be specified and implemented. This task depends on task 5 and runs in parallel with task 6 and 8.

8. Development-client

The development of the client software will be implemented by the contractee according to specification (task 2). It is estimated that at least 2 resources/persons will work fulltime on the development. Note that this task does not include implementing security solutions, encryption and digital signatures. This task depends on task 5 and runs in parallel with task 6 and 7.

9. Evaluate demonstrator

The Harmonization Group must test and evaluate the demonstrator. This evaluation will be used as input to faze 2. This task depends on task 8.

10. Demonstrator end - milestone

This milestone marks the end of phase 1 . This task depends on task 9.

\subsubsection{Phase 2: Pilot}

Based on the technical implementations of the demonstrator, a pilot will be executed. The pilot will include reporting of real data from a selection of companies, thus security will be added in this phase. Any shortcoming from the demonstrator will be corrected and the Nordic Product Registers must adapt their software to receive data from the new client.

The phase start is set to January 1. 2010. The end will be in Q4, 2010. 


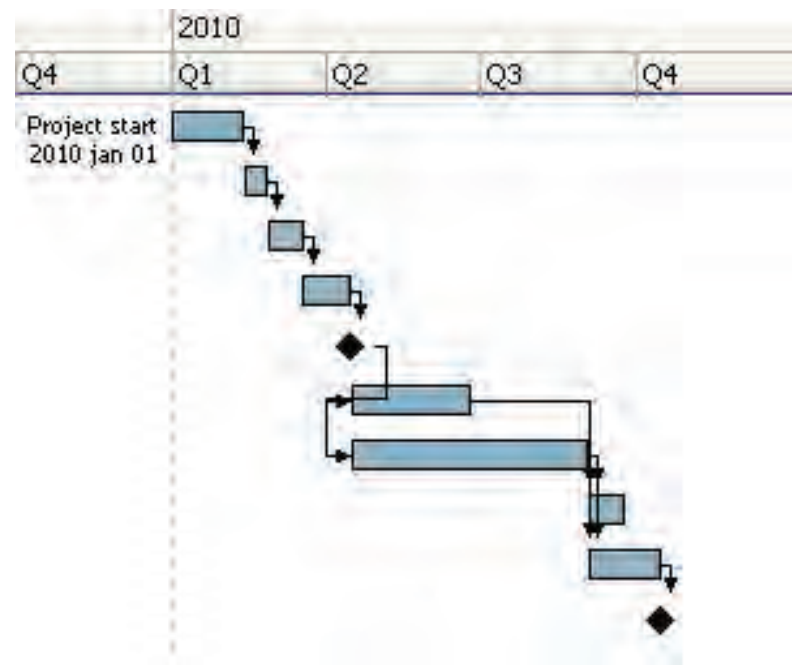

\section{Specification}

The requirements of the pilot need to be defined. This includes any technical and functional requirements to the solution. The major technical achievement in this phase is security.

\section{Announcement}

The project will be announced in this task. It depends on task 1 .

\section{Evaluation}

The answers from potential implementers must be evaluated. This task depends on task 2.

\section{Negotiations}

The Harmonization Group negotiates with one or several potentional providers. This task depends on task 3.

5. Contract-milestone

The first milestone is reached when a contract is made between the party who will develop the solution and the Harmonization Group. This task depends on task 4.

6. Development - client (security)

The client will be further developed. The major enhancement is implementation of security. Also bug fixes and corrections based on the demonstrator will be done during this task. This task depends on task 5 and runs in parallel with task 7.

\section{Development - Product Registers}

The Nordic Product Registers needs to adapt their software at the servers so that they may receive data from the new client. This task depends on task 5 and runs in parallel with task 6 . 
This task is the longest running task in this phase and may be cut down if more resources are located. Only one person at each Product Register has been used in the schedule and the phase is estimated to take 800 man-hours, since it is expected that the Product Registers will work in parallel, and 800 man-hours is the longest expected time for adaptation (Sweden).

\section{Report from companies}

A selection of companies will use the new client and report to the Product Registers. This task depends on task 5 and runs in parallel with task 6 and 7.

\section{Evaluate pilot}

An evaluation of the phase needs to be made. This evaluation will be used as input to the next phase. This task depends on task 5 and runs in parallel with task 6 .

10. Pilot end - milestone

This milestone marks the end of phase 2 and depends on task 9.

\subsubsection{Phase 3: Roll-out}

Based on phase 1 and 2, the solution needs to be rolled out to the companies. When this phase is completed, all companies in Denmark, Norway and Sweden may use the new, harmonized solution to report to the Nordic Product Registers.

Most of the activities in this phase could be done by the Nordic Product Registers themselves; therefore all tasks except 1, 5, 8 and 9 could be dropped. Task 6, which involves further development of the client, could be handled by the contract from phase 2 .

Phase start is set to January 1. 2011. Expected end is Q2 2011.

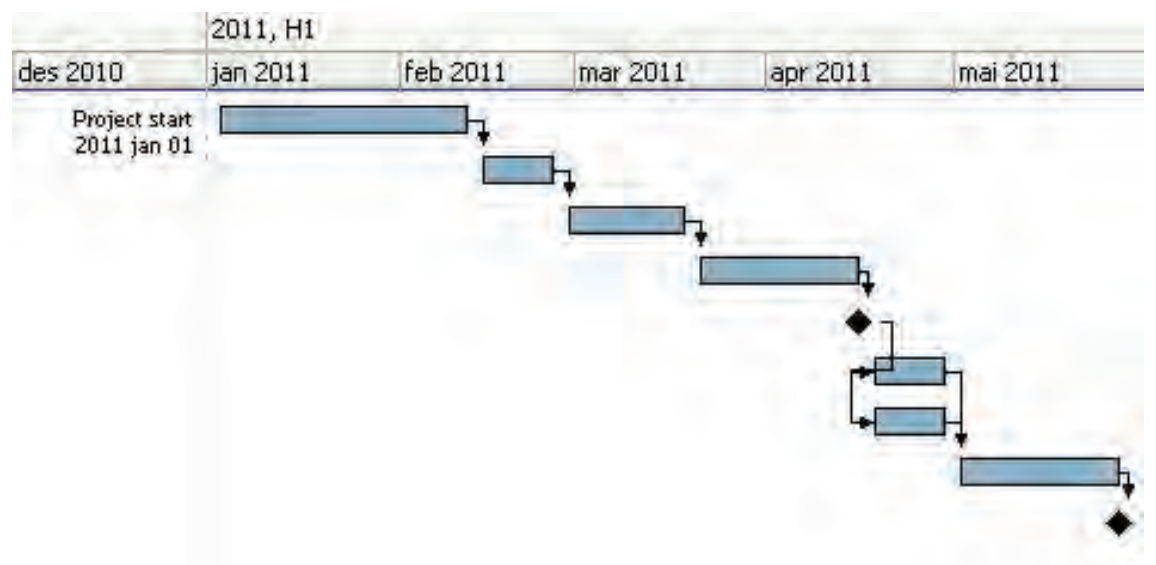




\section{Specification}

A specification of the work to be done in this phase must be planned and specified.

2. Announcement

Optional. The project will be announced in this task. It depends on task 1.

\section{Evaluation}

Optional. The answers from potential implementers must be evaluated. This task depends on task 2.

\section{Negotiations}

Optional. The Harmonization Group negotiate with one or several potentional providers. This task depends on task 3

5. Contract-milestone

Optional. The first milestone is reached when a contract is made between the party who will develop the solution and the Harmonization Group. This task depends on task 4

6. Development - client

This task will handle bug fixing, changes and/or any new functionality of the client. This task depends on task 5 and runs in parallel with task 7.

7. Development - servers

This task will handle bug fixing, changes and/or any new functionality of the software at the Product Registers internal systems. This task depends on task 5 and runs in parallel with task 6.

8. Roll-out

The client software is installed at the companies. This task should also involve any data conversion from the old solution to the new. This task depends on task 6 and 7.

9. Phase end - milestone

This milestone ends phase 3 . This task depends on task 8 . 


\section{Business models}

Part of this report is to discuss different models on how the implementation of the reference platform can be financed. This includes the actual development of the software and how maintenance cost can be supported after the initial development.

Development cost for the Product Registers, for instance adaptation to the server software, and the cost for finalizing the XML schema and to complete the specification of the harmonized solution, are excluded from these models. It is assumed that these are covered by the Nordic Product Registers themselves.

\subsection{Initial project funding}

The development of the reference model is an isolated task and it is possible to estimate quite accurate. Therefore this part of the project is suitable for external funding. Several sources for such funding might exist, and in this section we explore some of them.

\subsubsection{The Nordic Council}

The most obvious chose for funding would be from the Nordic Council, since the Harmonization Group is part of this organization. It is recommended that this should be the first choice to apply for funding.

\subsubsection{The Nordic Product Registers}

An option for funding of the project could be the Nordic Product Registers themselves. This funding has to be drawn from the annual budgets of the Product Registers.

Through discussion in this report's project group, it seems unlikely that the Nordic Product Registers are able, even if the motivation is present, to support the development of a harmonized solution. Therefore the most likely option will be to obtain some partial funding from the Nordic Product Registers.

\subsubsection{The industry}

The industry might also be an option to obtain funding. One option would be to make them pay a fee/subscription to report to the Product Registers. This is used in some countries today. Since this is a political sensitive 
decision to make, the probability of funding the project in this manner is estimated to be quite low.

Another option would be to seek funding in the industry's special interest groups. This could be a viable option, since these groups' motivation is to look after and make an impact in the marked for their members. However, no investigation has been made in to this matter.

\subsubsection{Research funds}

It is doubtful if this project can be classified as research, since these type of applications are quite common - at least the technical side.

The Research Council of Norway has an extensive list of research organizations in the Nordic countries, which could be used for cooperation and/or funding purposes, see: http://www.forskningsradet.no/no/

Organisasjoner+og+samarbeidsfora/1138785973118

Of course, it is possible also to apply for funds from the Research Council of Norway itself.

\subsubsection{Open Source funds}

The Ministry of Government Administration and Reform in Norway has launched a program to promote and encourage the development at use of Open Source Software and Open Standards. In this respect they have funded 15 public projects in Norway.

If the Nordic Product Registers decide to develop the solution as Open Source Software, base the solution on already developed Open Source Components/Software, and specify the use of Open Standards, it might be feasible to receive funding from the Ministry of Government Administration and Reform in Norway. It is unknown if similar opportunities exists in Denmark and Sweden.

It is not certain that the Ministry is still accepting applications at this point, but it could be investigated.

\subsubsection{EU funding:}

The $7^{\text {th }}$ Research Programme (FP7) of the European Union started in 2007 and will last until 2013. FP7 is divided into 4 main categories: Cooperation, Ideas, People, and Capabilities. Each of these is further divided into programmes.

Regarding the project of implementing the reference platform presented in this report, the Information and communication technologies programme in the Cooperation category seems most relevant.

See http://cordis.europa.eu/en/ for further information. 


\subsection{Consortium}

Since the development project will be a joint project between the product registers in Denmark, Norway and Sweden, it could be an idea to form a consortium which will administer the maintenance of the application. The task of this consortium would be to control and prioritise the funding. A natural choice for this kind of group would be the already existing Harmonization Group. 



\section{Success criteria and risks}

In order to evaluate the success and completeness of the proposed project, some success criteria and risks have been identified.

\subsection{Success criteria}

The success criteria are obviously strongly connected to the development of the client and that the XML schema becomes harmonized. Another success factor is that the industry will use the new technical to report to the Nordic Product Registers. Thus, it is recommended that the project will be evaluated from these criteria:

- Harmonization of XML schema is specified.

- One technical client is developed which is capable of reporting to the three Nordic Product Registers mentioned in this report.

- The percentage of electronically received reports using the new technology is the same or higher than the current percentage.

- The company that reports electronically today will use the new solution.

\subsection{Risks}

The following risks have been identified:

- Funding.

If a funding source is not found, the project will not be implemented. Also, how to finance the maintenance and support for the final application must be taken into account.

- Security.

If a common method for security (encryption, signatures, and certificates) is not used, this will make the project more expensive.

- If the project is divided into 3 phases/projects one must ensure that source code and documentation for each phase is available for the next phase, since different suppliers can be used in each phase. This point is, of course, also important for the final deliverance and if only the one-project solution is chosen. 



\section{References}

The Nordic Product Registers (2004), Oppsummering fra en liten markedsundersøkelse om felles nordisk elektronisk deklarering.

Andreas Ahrens and Antonia Reihlen (2007), The Nordic Product Registers and the future REACH substance database, TemaNord 2007:512, ISBN 978-92-893-1459-6.

The Nordic Product Registers (2007), A short presentation of the product registers in Denmark, Norway and Sweden.
Danish Product Register (2008), System documentation.

The Nordic Product Registers (2006), Description of entities and elements in the XML standard for exchange of chemical data.

The Nordic Product Registers (2007), Generell kommentar til utkast for et felles nordisk PRskjema.

Kemikalieinspektionen (2008), Tabellbeskrivning av delar av databasen KEOPS. 


\section{Norsk sammendrag}

Denne rapporten beskriver en softwaremodell for å implementere en harmonisert/felles rapporteringsmodul til de Nordisk produktregistre. Modulen skal brukes av den kjemiske industrien i de nordiske land til å deklarere kjemiske produkter til produktregistrene.

Det finnes flere måter å lage en slik modul på. Men i denne rapporten konkluderes det med at en ny modul basert på en tykk klient bør utvikles.

Rapporten inneholder også kostnadsestimat for utviklingen og foreslår to utviklingsmodeller for implementasjon. 